\title{
Community psychiatry: An audit of the services in southern Gauteng
}

M Y H Moosa, MMed Psych, FCPsych, MCFP

F Y Jeenah, MMed Psych, FCPsych

Department of Psychiatry, University of the Witwatersrand

Aim. To audit the community psychiatric services in southern Gauteng with a view to determining whether the objectives of the country's mental health legislation and policies are being achieved.

Results. Although southern Gauteng's community psychiatric clinics are situated in a primary health setting, primary health clinicians play no active role in the management of mentally ill patients. Care is supplied mainly by specialist psychiatrists, psychiatric registrars (in training) and psychiatric nurses. For first appointments, a mean of 2 patients are seen per doctor per clinic day for a mean duration of 30 minutes. For followup appointments, a mean of 17 patients are seen per doctor per clinic day for a mean duration of 8 minutes. The waiting time for new patient appointments is a mean of 6 months. Follow-up patients are seen once a month by nursing staff and approximately once every 4 months by doctors. An average of 1 in 5 patients is treated with oral atypical antipsychotics; in the majority of clinics, this is the total extent of care. However, where psychologists, social workers and occupational therapists are present, only $0.2 \%$ of all users have access to them.

Conclusion. The community psychiatric services, although better than those in some other countries, fall short of what is required by South African legislation and policies. General community health services ought to play an active role in the structure and delivery of psychiatric services by developing and strengthening the current limited services, with an emphasis on cost-effective and preventive approaches. Existing community psychiatric services, if so transformed, could serve as a model for other countries in Africa.

Mental illnesses result in severe distress, impaired productivity and diminished quality of life for the innumerable afflicted individuals and their families. The World Bank Report of $1993^{\prime}$ and the Harvard World Mental Health Report of $1996^{2}$ indicated that about $28 \%$ of all disabilities comprise mental illnesses and, furthermore, that 5 of the top 10 causes of disability are mental health problems. The reports projected that by the year 2020 mental health problems would comprise about 15\% of the gross burden of diseases, and much more heavily to total disabilities.

Although there are no published data on the burden of mental illnesses in South Africa, the epidemiology of mental health disorders in South Africa is similar to that found in developed countries. Rapid urbanisation has exacerbated unemployment, violence, substance abuse, child abuse, HIV/AIDS and the disintegration of traditional social support networks and families. These factors probably contribute to the increasing incidence of mental disorders.

In the second half of last century, mental health care underwent restructuring on an international level. Mentally ill patients had been previously confined to 'institutions'; these were generally inefficient and authoritarian, with impenetrable barriers to the outside world, had various rituals and required huge expenditure. Patients developed institutional neuroses characterised by symptoms such as apathy, lack of initiative, loss of interest and submissiveness. ${ }^{3}$ More recently, institutions began to be replaced by 'the community', a concept encouraging the development of alternative services including psychiatric units in general hospitals, community-based clinics, residential homes and day centres.

Mental health services in South Africa followed these international trends and were further supported by policy changes and new legislation. The White Paper for the transformation of health ${ }^{4}$ proposed a comprehensive, planned and co-ordinated communitybased mental health service at national, provincial, district and community levels. The new Mental Health Care Act ${ }^{5}$ required that mental health services improve through a primary health care approach with an emphasis on community care. All these features were incorporated into a strategic objective of the Department of Health. ${ }^{6}$

It is evident that the main thrust of mental health care in South Africa had its foundations in community-based services; this resulted in a rapid process of de-institutionalisation - large numbers of chronically mentally ill patients were discharged from institutions for care within the community. However, concerns arose that, prior to the transformation processes, there was a lack of development of new services or strengthening of existing psychiatric services within the community. The funds that accrued from the de-institutionalisation process were not transferred to, nor were additional funds budgeted to bolster, the community-based services. 
The foregoing facts motivated the opportunity and need to audit psychiatric services in a community-based setting. The basis for this evaluation was the community psychiatric services for adults in southern Gauteng because these were the most developed services in the country. Although the findings are not generalisable, they may provide some pertinent information and serve as a basis for further regional studies.

\section{Aim}

The objective of this study was to describe the southern Gauteng community psychiatric services with regard to geographical distribution, staff establishments and utilisation.

\section{Method}

The study comprised a retrospective audit of community psychiatric services in southern Gauteng in 2005. The services are co-ordinated by the District Mental Health programme managers and the Division of Psychiatry at the University of the Witwatersrand. These authorities were consulted to obtain data on the geographical distribution of the services, service packages and staff establishments of the various clinics, and the psychotropic medications available for prescribing by doctors. Patient statistics were obtained from Human Information Systems at the offices of the regional directorates, and included the number of patients per month attending psychiatric clinics in the various districts. Information on psychotropic medication usage was obtained from the Medical Supplies Depot.

Attendance figures and staff complements at all clinics in the studied region were combined and expressed as means and averages across all the services. Descriptive statistics were computed as counts, percentages and means. All analyses were done using Statistical Package for Social Sciences 10.0 for Windows (SPSS Inc., Chicago, III.).

A limitation of this study is that assumptions and generalisations are statistically weak, and that contact time by clinicians is not necessarily an ideal measure of service delivery. However, we believe they are worth noting.

\section{Results}

\section{Geographical distribution}

Community psychiatric services for adults (>18 years old) are provided by the District Health Services. Southern Gauteng region is divided into 4 districts: Johannesburg Metro, Westrand,
Ekhuruleni and Sedibeng. The adult population of the 4 districts, according to Census South Africa 2001, ' was 2579767 (Metro), 514459 (Westrand), 1941186 (Ekhuruleni), and 576125 (Sedibeng), respectively. Most of the psychiatric clinics are located within primary health clinics (Table I). Although there are 21 clinics in the Johannesburg Metro, they are concentrated in the south, with a paucity of services in the northern segment of southern Gauteng (Table I).

\section{Staff establishments}

The Norms and Standards for Mental Health Care for people with severe psychiatric conditions were commissioned by the Directorate: Mental Health and Substance Abuse, Department of Health, in 1998. This tool is used to calculate acceptable levels of mental health care and human resources required for ambulatory care per 100000 people. The minimum acceptable staffing norms thus calculated, and the multidisciplinary staff that provided services in 2005 in the districts, are listed in Table II.

Although the clinics are located in a primary health setting, primary health care professionals play no active role in the management of mentally ill patients. Care is supplied mainly by specialist psychiatrists, psychiatric registrars (in training), and psychiatric nurses with minimal - if any - support from psychologists, social workers and occupational therapists.

\section{Utilisation of services}

Based on clinic rosters, we established that psychiatry registrars and/or nurses provide care at these clinics ranging from 1 day per week to 1 day per month. The mean monthly attendance figures in the various clinics in the districts are listed in Table III. An average of 2 first-appointment patients are consulted per doctor per clinic day. The mean duration of first appointments is 30 minutes, and the wait time is 6 months. Follow-up appointments by doctors and nurses are, on average, once every 4 months and once a month, respectively. The mean duration of a followup appointment is 8 minutes for doctors and 10 minutes for psychiatric nurses. Psychologists, social workers and occupational therapists are not available at all facilities; only 1 in 500 of all users has access to them.

Psychotropic drugs available in the services are in accordance with the Essential Drug List (EDL) for Gauteng. This list was expanded in 2004 to include newer psychotropics with restrictions (Table IV).

The antipsychotics used are: oral typical (haloperidol, triluperazine and chlorpromazinel - 59.8\%; intramuscular depot typical 
Table I. Adult clinics in southern Gauteng

\begin{tabular}{|c|c|c|c|}
\hline Metro & Westrand & Ekhuruleni & Sedibeng \\
\hline Brixton & Azaadville & Actonville & Boipatong \\
\hline Diepkloof & Brakpan & Boksburg & Empilisweni \\
\hline Discoverers & Carletonville & Brakpan & Johan Heyns \\
\hline Dobsonville & Hekpoort & Daveyton & Kookrus \\
\hline Eldorado Park & Kagiso & Devon & Kopanong \\
\hline Ennerdale & Khutsong & Duduza & Levai Mbatha \\
\hline Hillbrow & Krugersdorp & Eden Park & Ratanda \\
\hline Ivory Park & Mogale & Etwatwa & Sharpeville \\
\hline Jeppe & Mohlakeng & Germiston & Tabitha Oord \\
\hline Lenasia & Munsieville & Goba & Vereeniging \\
\hline Lilian Ngoyi & Randfontein & Kempton Park & \\
\hline Meadowlands & Swanieville & Kwa-Thema & \\
\hline Mofolo & Toekomsrus & Nigel & \\
\hline Orange Farm & Westonaria & Northmead & \\
\hline Orlando & & Springs & \\
\hline Pimville & & Tembisa CHC & \\
\hline Rabie Ridge & & Thokoza/Dresser & \\
\hline Riverlea & & Tsakane & \\
\hline Townsview & & Vosloorus & \\
\hline Westbury & & Zonkesizwe & \\
\hline Zola & & & \\
\hline
\end{tabular}

\section{Table II. Minimum staffing norms and staff establishments for 2005}

\begin{tabular}{|c|c|c|c|c|c|c|c|c|}
\hline \multirow[b]{2}{*}{ Category } & \multicolumn{4}{|c|}{ Minimum norm (per population) } & \multicolumn{4}{|c|}{ Actual staff establishment } \\
\hline & Metro & Westrand & Ekhuruleni & Sedibeng & Metro & Westrand & Ekhuruleni & Sedibeng \\
\hline Psychiatric nurses & 39 & 12 & 39 & 12 & 31 & 8 & 31 & 8 \\
\hline Occupational therapists & 29 & 3 & 10 & 3 & 0 & 0 & 1 & 0 \\
\hline Social workers & 19 & 6 & 19 & 6 & 2 & 0 & 2 & 0 \\
\hline Psychologists & 19 & 6 & 19 & 6 & 3 & 0 & 3 & 1 \\
\hline Psychiatrists & 6 & 1 & 5 & 3 & 2 & 0 & 1 & 2 \\
\hline Medical officers & 11 & 3 & 10 & 3 & 6 & 3 & 5 & 2 \\
\hline
\end{tabular}

\section{Table III. Mean monthly attendance figures in the districts for 2005}

\begin{tabular}{lcccr}
\hline \multicolumn{1}{l}{ Table III. Mean monthly attendance figures in the districts for $\mathbf{2 0 0 5}$} \\
\cline { 2 - 5 } & \multicolumn{4}{c}{ Districts } \\
\cline { 2 - 5 } & Metro & Westrand & Ekhuruleni & Sedibeng \\
\hline Total number of patients & 9573 & 3015 & 6067 & 2894 \\
Number of patients seen by nursing staff & 6989 & 2214 & 4349 & 2159 \\
Number of patients seen by registrars & 2584 & 801 & 1718 & 735 \\
Number of new patients seen by registrars & 396 & 121 & 179 & 115 \\
\hline
\end{tabular}




\begin{tabular}{|c|c|c|c|}
\hline Level of care & Primary level (any doctor) & & $\begin{array}{l}\text { Secondary level } \\
\text { (psychiatrist only) }\end{array}$ \\
\hline \multirow[t]{5}{*}{ Anti-depressants } & & & Clomipramine tabs 10 \\
\hline & Imipramine tabs 10, 25 mg & & $25 \mathrm{mg}$ \\
\hline & Amitrlptyline tabs 25 mg & & Paroxetine tabs $20 \mathrm{mg}$ \\
\hline & Fluoxetine tabs 20 mg & & Citalopram tabs 20 mg \\
\hline & & & $\begin{array}{l}\text { Mianserin tabs } \\
10,30 \mathrm{mg}\end{array}$ \\
\hline \multirow[t]{3}{*}{ Hypnotics/anxiolytics } & $\begin{array}{l}\text { Diazepam tabs } 5 \mathrm{mg} \text { and } \\
\text { injection } 10 \mathrm{mg} / 2 \mathrm{ml}\end{array}$ & & Buspirone tabs $10 \mathrm{mg}$ \\
\hline & Lorazepam inj. 4 mg/ml & Lorazepam tabs 1, $2.5 \mathrm{mg}$ & \\
\hline & $\begin{array}{l}\text { Oxazepam tabs } \\
10,15,30 \mathrm{mg}\end{array}$ & & \\
\hline \multirow[t]{7}{*}{ Neuroleptics } & Zuclopenthixol acetate & & \\
\hline & 50 mg/ml & & Risperidone tabs 3 mg \\
\hline & $\begin{array}{l}\text { Chlorpromazine tabs } \\
25,100 \mathrm{mg}\end{array}$ & & $\begin{array}{l}\text { Trifluoperazine tabs } \\
1,5 \mathrm{mg}\end{array}$ \\
\hline & $\begin{array}{l}\text { Haloperidol tabs } \\
0.5,5 \mathrm{mg} \text { and inj. } 5 \mathrm{mg} / \mathrm{ml}\end{array}$ & Haloperidol tabs $1.5 \mathrm{mg}$ & $\begin{array}{l}\text { Zuclopenthixol tabs } \\
2,10 \mathrm{mg} \text { and } 200 \mathrm{mg} / \mathrm{ml} \\
\text { depot inj. }\end{array}$ \\
\hline & $\begin{array}{l}\text { Flupenthixol depot inj. } 20 \text { mg/ml, } \\
40 \mathrm{mg} / \mathrm{ml}\end{array}$ & & $\begin{array}{l}\text { Thioridazine } 10 \text { mg tabs, } \\
100 \mathrm{mg} \text { tabs }\end{array}$ \\
\hline & $\begin{array}{l}\text { Fluphenazine depot inj. } \\
25 \mathrm{mg} / \mathrm{ml}\end{array}$ & & $\begin{array}{l}\text { Clozapine tabs } \\
25,100 \mathrm{mg}\end{array}$ \\
\hline & & & Sulpiride tabs 200 mg \\
\hline Stimulants & & & $\begin{array}{l}\text { Methylphenidate tabs } \\
10 \mathrm{mg}\end{array}$ \\
\hline \multirow[t]{2}{*}{ Mood stabilisers } & $\begin{array}{l}\text { Carbamazepine tabs } 200 \text { mg, } \\
\text { syrup } 100 \mathrm{mg} / 5 \mathrm{ml}\end{array}$ & & $\begin{array}{l}\text { Lithium carbonate tabs } \\
250,400 \mathrm{mg}\end{array}$ \\
\hline & $\begin{array}{l}\text { Valproate sod. tabs } \\
200,500 \text { mg, syrup } 200 \text { mg/5ml, } \\
\text { Valproic acid caps } 500 \text { mg }\end{array}$ & $\begin{array}{l}\text { Valproic acid caps 150, } \\
300 \text { mg }\end{array}$ & \\
\hline \multirow[t]{2}{*}{ Anti-parkinsonian agents } & Biperiden inj. 5 mg/ml & & Biperiden tabs 2 mg \\
\hline & Orphenadrine tabs 50 mg & & \\
\hline Psychosexual problems & & & $\begin{array}{l}\text { Cyproterone acetate } \\
\text { tabs } 50 \mathrm{mg} \text { and depot } \\
\text { inj. }\end{array}$ \\
\hline Alcohol abuse & & & Disulfiram tabs 400 mg \\
\hline
\end{tabular}

(flupenthixol, zuclopenthixol) - 17.3\%; and oral atypical (sulpiride, clozapine, risperidone) $-22.9 \%$. The antidepressants used are tricyclics (amitriptyline, clomipramine) and selective serotonin re-uptake inhibitors (fluoxetine, citalopram, paroxetine). 


\section{Discussion}

The fundamental principles of community psychiatry include: comprehensive services, with treatment reasonably close to the patient's home; continuity of care; and patient participation. ${ }^{8}$ Psychiatrists in a community setting, in addition to direct clinical care, are expected to provide home assessments and reviews, psycho-education and early detection screening of most psychiatric disorders. ${ }^{9.11}$ They are meant to work in partnership with medical specialists, family caregivers, special needs groups, and public and private agencies in the community. Furthermore, community psychiatric services are also intended to improve the mental health wellbeing of the community by promoting mental health awareness, teaching skills to develop resilience, and challenging stigmatisation. ${ }^{12}$

It would appear from our audit that community psychiatric services in southern Gauteng do not meet all the principles and objectives described above. There are insufficient numbers of community psychiatric clinics to meet the needs of the ever-increasing population of the area. The few clinics in operation are not geographically accessible to all users, are moreover servicing excessively large numbers of patients, and may not be able to deal effectively and comprehensively with their mental health problems in the short contact time available.

Moreover, staff complements are considerably less than the minimum norms recommended by the Department of Health. Specialised psychiatric personnel provide their services only once a week or once a month, and there is little or no support for patients at other intervals. The predominant focus is on direct clinical care with a limited choice of psychotropic medication. There are minimal (if any) multidisciplinary approaches to care, rehabilitation and integration of users back into society.

For the large population in this region, there is inadequate provision of community mental health services, and modern psychiatry does not seem to exist for them. For those patients entering the system, there is insufficient ongoing care, monitoring and psychosocial support.

\section{Recommended strategies to improve services}

National mental health policy must be formulated by professionals from the field of mental health as well as public health administration, economics, education and social sciences. Mental health clinics that are geographically accessible to all users need to be established or developed in all districts. The services should incorporate district and regional hospitals so that a system of networking and referral at all levels exists, and all facilities be supported with human and material resources in accordance with the national staffing norms. Active recruitment and retention, through incentive-based approaches, of specialised personnel to work in the community may be considered. In order to achieve these objectives, services have to be adequately financed; the budgets from shut-down institutions should be made available to community services.

The World Health Organization (WHO) Expert Committee (1975)'13 stated: 'In the developing countries, trained health professionals are very scare indeed; clearly, if proper health care is to be brought within reach of the mass of the population, this will have to be done by non-specialized health workers at all levels, from the primary health workers to the nurse or doctor working in collaboration with and supported by more specialized personnel. Primary health care workers would need to be trained and provided with guidelines on the principles of basic mental health care. Inherent in this concept is that specialized/teaching institutions should assume a role of providing technical input in the form of human resource development, capacity building, evaluation and development of locally acceptable models of care to enable the system to become strong and dynamic. The approach will not only relieve the congestion at the teaching hospitals but also provide health care assistance at an early stage with tremendous costeffectiveness in the long run.

The World Psychiatric Association (WPA) and the Londonbased National Institute of Clinical Excellence (NICE) issued evidence-based guidelines in 2002 which recommended that oral 'atypical' antipsychotic drugs be considered as the first-line choice of treatment for newly diagnosed schizophrenia and for patients with unacceptable adverse effects caused by 'typical' agents. It is imperative that a wider choice of the newer atypical antipsychotics and antidepressants be made freely available for clinicians to prescribe according to guidelines.

In collaboration with other sectors such as education, social welfare, medical education, legal agencies and other nongovernmental organisations, the mental health care programme would become more comprehensive and effective in achieving its targets.

\section{Conclusion}

Health is held to be a fundamental birthright of every individual. Mental health policies should conform to general socio-political and moral precepts and scientific disciplines. Policymakers must seek informed opinion, active involvement and co-operation 
from professionals and the public. This approach should also be reflected in the structure and functions of clinics, with evidence of the development and strengthening of resources in these units. Furthermore, greater emphasis should be placed on cost-effective, active and preventive approaches, and due consideration be given to the established norms and customs of the local population. The local community psychiatric services, thus transformed, could serve as a model for other African countries.

\section{References}

1. World Bank. World Development Report. Washington: World Bank, 1993.

2. Murray CJL, Lopez AD. Harvard World Mental Health Report (1996). Global Burden of Disease Study Conducted by the World Health Organization, World Bank, and Harvard University. Cambridge, Mass: Harvard University Press, 1996: 14, 131.

3. Barton R. Institutional Neurosis. 3rd ed. Bristol: John Wright, 1976: 47

4. White Paper for the Transformation of the Health System in South Africa. Pretoria: Department of Health, 1997. http://www.info.gov.za/whitepapers/1997/health htm (accessed 14 April 2008).
5. Mental Health Care Act No. 17 of 2002. Chapter II: Fundamental Provisions. Government Gazette vol. 449. Pretoria: Government Printer, 6 November 2002 http://www.info.gov.za/gazette/acts/2002/a 17-02.pdf (accessed 14 May 2008)

6. A National Health Plan for South Africa. Prepared by the ANC with the technical support of WHO and UNICEF. May 1994. www. anc.org.za/ancdocs/policy/ health.htm (accessed 14 May 2008).

7. South Africa: Population Census 2001. Community profile database. Pretoria: Statistics SA. http:// www.statssa.gov.za/census $01 / \mathrm{html} /$ default.asp laccessed 14 May 2008).

8. Caplan G, Caplan R. Principles of community psychiatry. Community Ment Health J 2000; 36: 7-24

9. Rosen A. The community psychiatrist of the future. Curr Opin Psychiatr 2006; 19 : 380-388

10. Faloon IRH, Montero I, Sunger M, et al. Implementation of evidence-based treatment for schizophrenic disorders: two-year outcome of an international field trial of optimal treatment. World J Psychiatr 2004; 3: 104-109.

11. Johnson S, Nolan F, Hoult J, et al. Outcomes of crises before and after introduction of a crisis resolution team. BrJ Psychiatr 2005; 187: 68-75.

12. Rosen $A$. What developed countries can learn from developing countries in challenging psychiatric stigma. Australasia Psychiatry 2003; 11:589-595.

13. Organisation of Mental Health Services in Developing Countries. Sixteenth Report of the WHO Committee on Mental Health. Geneva: World Health Organization, 1975. 